\title{
Induced glare testing — an underutilized test in evaluating visual disability in patients presenting with symptomatic cataracts
}

\author{
Satheesh Solomon T. Selvin $\odot^{1}$, Abhriya Dey ${ }^{2,1}$, Chris Elsa Samson Jacob ${ }^{3,1}$, Thomas Kuriakose ${ }^{1}$ \\ 'Department of Ophthalmology, Christian Medical College, Vellore, India \\ ${ }^{2}$ Mission of Mercy AG Hospital, Kolkata, West Bengal, India \\ ${ }^{3}$ Sankara Nethralaya, Chennai, Tamil Nadu, India
}

\begin{abstract}
BACKGROUND: Cataract increases intraocular light scatter which affects the retinal image contrast and sensitivity. Symptomatic patients with cataract complain of a drop in the quality of vision or glare affecting daily routine even with preserved visual acuity. This study was aimed to quantify the drop in the glare induced visual acuity (VA) and contrast sensitivity (CS) in different morphological types of cataracts.

MATERIAL AND METHODS: This was an observational study on a prospective cohort, conducted at a tertiary-care centre in South-India. Patients admitted for cataract surgeries between March and September 2017 with BCVA $\geq$ $6 / 60$ (Snellen) and $\geq 40$ years were enrolled. LogMAR VA and CS were measured pre and post-operatively, with and without glare induction using brightness acuity tester. Patients were sub-categorised based on morphology and the presence of glare as a symptom. Paired-t test for the pre- and post-operative values and analysis with Bonferroni's adjustment were the statistical methods used.

RESULTS: Data of 78 patients were sub-categorised and analysed. Glare induction with high glare was significant in all the studied groups. LogMAR VA was affected most in group $3(0.20,10$ letters, $\mathrm{p}<0.05)$ and the CS in group $2(0.62,4.1$ step drop, $\mathrm{p}<0.05)$. Patients who had glare as a symptom had an average greater drop in LogMAR VA $(0.30, \mathrm{p}=0.01)$ and $\mathrm{CS}(-0.29, \mathrm{p}=0.03)$ when induced with a high glare.

CONCLUSIONS: All morphological types of cataracts affect VA and CS to a greater extent in conditions of bright lighting. Glare induced VA and CS testing is a sensitive and an adjunct tool to traditional high contrast VA testing, in evaluating the visual dysfunction of patients presenting with symptomatic cataracts.
\end{abstract}

KEY WORDS: brightness acuity tester; cataract; contrast sensitivity; glare, logMAR

Ophthalmol J 2020; Vol. 5, 107-113

\section{INTRODUCTION}

Visual acuity (VA) is a special sense and a decrease in which can result in difficulties of all functional domains of day-today activities. The visual experience of a human eye is not just isolated to the VA alone but involves the various attributes of vision [1-3]. The physiology of the visual system is a series of complex tasks, which includes the transmission of visual sensations forming representations, stereopsis, perception of movement, colour vision, contrast perception etc [1-6].

Ocular pathologies with media opacity lead to light scattering resulting in glare and affects the contrast of the visual scene for the individual. Contrast 
sensitivity (CS) is the ability to discern and detect an object against its background whereas glare is the contrast reducing effect secondary to stray light in the visual scene [7-9]. Individual variations are seen with CS and it physiologically declines with age whereas glare could become bothersome depending on its severity and the individual needs. Cataract is the most common condition which results in increased intraocular light scatter affecting the CS and thereby the quality of the visual perception and the image [10-14]. Visual acuity though is the traditional standard measure of visual function, is retained till advance stages of cataracts, even in the presence of other visual complaints $[14,15]$ The advice on surgery largely depends on the measured VA in most hospitals and has become the sole criteria to advice the patient.

A brightness acuity tester (BAT) with a standardized glare induction can measure the drop in glare-induced VA and CS $[16,17]$. A measure of these parameters when compared to the post-operative recovery will provide information about the visual disability of the patients, which retrospectively will quantify as the extent of visual quality deterioration. In our study, we evaluated and quantified glare induced degradation of VA (LogMAR - logarithm of the minimum angle of resolution) and CS (Pelli-Robson chart) in patients who were admitted for cataract surgeries.

\section{MATERIAL AND METHODS}

This was an observational study on a prospective cohort of patients, conducted at a tertiary care centre in southern India between March and September 2017. The study was approved by the Institutional Review Board and the Ethics Committee and followed the Tenets of the Declaration of Helsinki.

\section{SAMPLE SIZE CALCULATION}

We needed to study 77 patients (eyes) to study a difference of 0.8 between the pre and post-operative ( $90 \%$ power at a $5 \%$ level of significance). The sample size was calculated based on the study by Wood et al [18]. We enrolled 90 patients with an assumption of about $15-20 \%$ as the drop-out rate during follow up.

\section{ENROLLMENT}

Patients admitted for cataract surgeries during the study period were enrolled after informed consent. Demographic data and symptomatology pertaining to cataract affecting their daily routine were collected. Patients with best corrected visual acuity (BCVA) of Snellen equivalent of $6 / 60$ or better, and above 40 years with the ability to read English alphabets were identified and included in the study. Patients with corneal degenerations, dystrophies or scars in the visual axis, synechiae and abnormalities of pupil, retinal and optic nerve pathologies were excluded. Other exclusion criteria included were the usage of dilating drops in the preceding 48 hours and dilated or non-reacting pupil as these could exaggerate the glare perception.

\section{METHODOLOGY}

All patients who were enrolled underwent BCVA measurement with LogMAR chart (Weber contrast 97\%, Appasamy I Chart Lite, $100 \mathrm{~cd} / \mathrm{m}^{2}$ ) by the primary investigator. Patients had their CS measurement with the Pelli-Robson chart $\left(3 \mathrm{~m}, 80 \mathrm{~cd} / \mathrm{m}^{2}\right)$ following which the LogMAR vision and CS were measured again in low-glare (10 foot-lamberts) and high-glare (100 foot-lamberts) respectively using a BAT (Marco, BAT-2000, Jacksonville, Florida) by the co-investigator. The horizontal pupillary diameter was then measured (NIDEK Optical Biometry, Nidek CO., Ltd., Japan Model 2000) under normal room lighting conditions (LUX $32 \mathrm{~cd} / \mathrm{m}^{2}$ ) by the primary investigator. The luminance was measured with the Secure Life Illumination meter (Class B per DIN 5032-7, Gossen Mavolux Ltd.). Patients were examined for the type and the morphology of the cataract by a single ophthalmologist (Slit-lamp, HAAG Streit, International 10) using LOCS III (Lens Opacities Classification System III). To avoid observation bias, the measurements were done independently and all three investigators were blinded from each other's readings. Patients underwent their planned surgeries and all the readings were repeated with the same protocol at the scheduled follow up visit between $6 \pm 1$ weeks following their cataract surgeries. Further, at follow up, the resolution of the symptoms were recorded in a Likert Scale of 0 to 10 with 10 being the complete resolution of the same.

\section{STATISTICAL ANALYSIS}

Data was entered into Microsoft Excel and analysed using STATA/IC 13.1. Data was summarised using mean (standard deviation) for continuous variables and frequency (\%) for categorical variables. Continuous variables were analysed using ANOVA, categorical variables using paired-t-test for pre and post-operative differences and statistical significance kept at $5 \%$ level $(\mathrm{p}<0.05)$. Bonferroni 
correction adjustment was applied for the analysis of the measured values between groups.

\section{RESULTS}

Ninety patients were enrolled in the study of which 12 patients did not follow up as per the study protocol as defined in the study; data of 78 patients were analysed. The mean age of the participants was 61.68 years (range $41-80$ years). Primary complaints were either decreased vision or glare with 47 patients in our study population had both the symptoms. Almost $70 \%$ of our study population (54 patients) experienced glare from the headlamps of the oncoming vehicles or on exposure to bright sunlight. Of the patients who had glare, 20 patients drove vehicles on a regular basis, and all of them experienced troubling glare from headlights of the oncoming vehicles. Forty-six of the 54 patients who had symptoms of glare had a component of posterior sub-capsular cataract. All except three patients had a complete reduction of glare postoperatively, and the three patients had reported a score of 5 on a Likert Scale of 0 to 10 for reduction of glare post-operatively. The evaluation revealed two patients having minimal residual central striate keratopathy involving the pupillary axis and one with an IOL dislocation with a fixed mid-dilated pupil of $4.1 \mathrm{~mm}$, as the possible reasons for the residual complaints of glare.

Patients were grouped based on the morphological type of cataracts - nuclear sclerosis (NS) - Group 1 (20 patients, 25.64\%), posterior capsule cataract (PSC) - Group 2 (11 patients, 14.10\%) and a combination of nuclear sclerosis with posterior capsule cataract (NS + PSC, Group 3, 47 patients, $60.26 \%$ ). Presence of cortical opacities in the central $3 \mathrm{~mm}$ zone (visual axis) was also noted. The mean pre-operative horizontal pupillary diameter as measured with Optical Biometer, was $2.87 \mathrm{~mm}$ $(\mathrm{SD} \pm 0.08)$ and post-operatively was $3.17 \mathrm{~mm}$ $(S D \pm 0.08)$ and the mean difference of $0.3 \mathrm{~mm}$ between the subgroups was clinically negligible and not statistically significant.

Table 1 gives an overview of the raw data of the mean values of the LogMAR and the CS val-

Table 1. Raw data of the mean values of the LogMAR and contrast sensitivity (CS) induced with low and high-glare with the brightness acuity tester in the various study groups

\begin{tabular}{|c|c|c|c|c|c|c|}
\hline & LogMAR Vision & $\begin{array}{l}\text { LogMAR vision } \\
\text { in low glare }\end{array}$ & $\begin{array}{l}\text { LogMAR vision } \\
\text { in high glare }\end{array}$ & $\begin{array}{l}\text { Contrast } \\
\text { sensitivity }\end{array}$ & $\begin{array}{c}\text { Contrast } \\
\text { sensitivity } \\
\text { in low glare }\end{array}$ & $\begin{array}{c}\text { Contrast } \\
\text { sensitivity } \\
\text { in high glare }\end{array}$ \\
\hline \multicolumn{7}{|c|}{$\begin{array}{l}\text { Preoperative measurements } \\
\text { Mean values ( } \pm \text { SD) }\end{array}$} \\
\hline $\begin{array}{l}\text { Group } 1 \\
(\mathrm{n}=20)\end{array}$ & $0.35(0.15)$ & $0.36(0.13)$ & $0.51(0.26)$ & $1.11(0.32)$ & $1.10(0.33)$ & $0.61(0.41)$ \\
\hline $\begin{array}{l}\text { Group } 2 \\
(\mathrm{n}=11)\end{array}$ & $0.37(0.24)$ & $0.38(0.24)$ & $0.51(0.44)$ & $1.03(0.39)$ & $1.02(0.39)$ & $0.41(0.51)$ \\
\hline $\begin{array}{l}\text { Group } 3 \\
(\mathrm{n}=47)\end{array}$ & $0.52(0.22)$ & $0.53(0.21)$ & $0.72(0.35)$ & $0.80(0.38)$ & $0.79(0.40)$ & $0.26(0.33)$ \\
\hline $\begin{array}{l}\text { Total } \\
(\mathrm{n}=78)\end{array}$ & $0.46(0.22)$ & $0.46(0.22)$ & $0.64(0.36)$ & $0.91(0.40)$ & $0.91(0.41)$ & $0.37(0.41)$ \\
\hline \multicolumn{7}{|c|}{$\begin{array}{l}\text { Post-operative measurements } \\
\text { Mean values ( } \pm \text { SD) }\end{array}$} \\
\hline $\begin{array}{l}\text { Group } 1 \\
(\mathrm{n}=20)\end{array}$ & $0.08(0.11)$ & $0.08(0.11)$ & $0.11(0.13)$ & $1.52(0.25)$ & $1.52(0.25)$ & $1.29(0.26)$ \\
\hline $\begin{array}{l}\text { Group } 2 \\
(\mathrm{n}=11)\end{array}$ & $0.09(0.16)$ & $0.08(0.15)$ & $0.10(0.16)$ & $1.60(0.16)$ & $1.56(0.12)$ & $1.47(0.22)$ \\
\hline $\begin{array}{l}\text { Group } 3 \\
(\mathrm{n}=47)\end{array}$ & $0.10(0.11)$ & $0.10(0.11)$ & $0.10(0.13)$ & $1.43(0.24)$ & $1.44(0.24)$ & $1.27(0.23)$ \\
\hline $\begin{array}{l}\text { Total } \\
(\mathrm{n}=78)\end{array}$ & $0.10(0.12)$ & $0.10(0.12)$ & $0.11(0.14)$ & $1.48(0.24)$ & $1.49(0.24)$ & $1.31(0.25)$ \\
\hline
\end{tabular}

SD — standard deviation 


\begin{tabular}{|c|c|c|c|}
\hline \multirow[b]{2}{*}{ Pre-operative values } & \multicolumn{3}{|c|}{ Glare as a symptom at presentation } \\
\hline & $\begin{array}{c}\text { Present }(n=53) \\
\text { Mean }( \pm \text { SD) }\end{array}$ & $\begin{array}{c}\text { Absent }(n=25) \\
\text { Mean }( \pm \text { SD) }\end{array}$ & $\begin{array}{l}\text { Difference } \\
\text { (p value) }\end{array}$ \\
\hline LogMAR vision & $0.51(0.21)$ & $0.35(0.20)$ & $0.16(0.04)$ \\
\hline LogMAR vision in low glare & $0.51(0.21)$ & $0.37(0.19)$ & $0.14(0.05)$ \\
\hline LogMAR vision in high glare & $0.70(0.35)$ & $0.40(0.18)$ & $0.30(0.01)$ \\
\hline Contrast sensitivity & $0.85(0.39)$ & $1.04(0.42)$ & $-0.19(0.04)$ \\
\hline Contrast sensitivity in low glare & $0.84(0.38)$ & $1.03(0.43)$ & $-0.19(0.04)$ \\
\hline Contrast sensitivity in high glare & $0.30(0.37)$ & $0.59(0.45)$ & $-0.29(0.03)$ \\
\hline
\end{tabular}

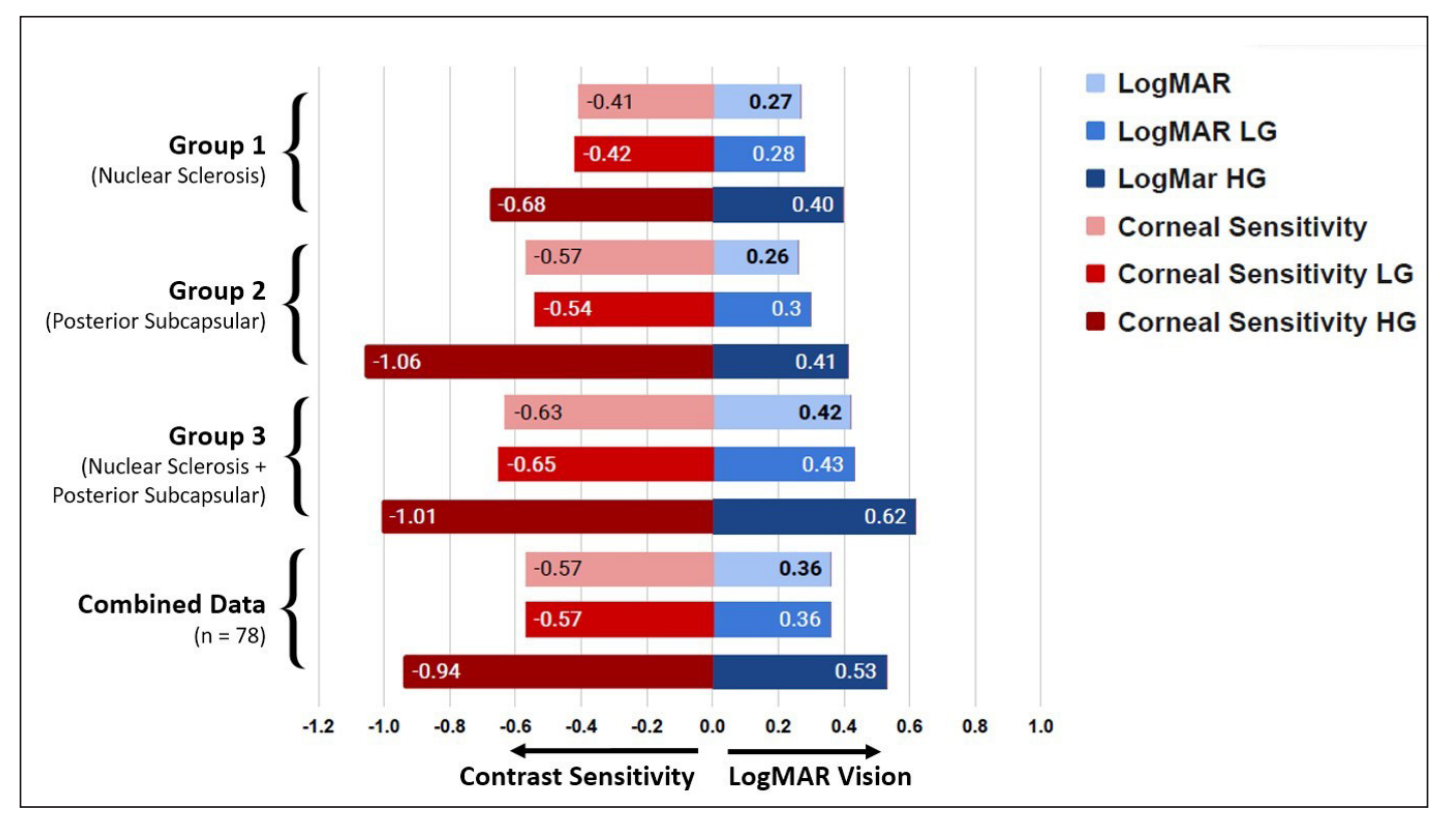

FIGURE 1. Difference between the pre and post-operative values of the LogMAR vision and the contrast sensitivity with and without induction of low glare (LG) and high glare (HG)

Table 3. Odds ratio of the presence of glare as a symptom to the various morphological types of cataracts in the study population

\begin{tabular}{|l|c|c|c|c|c|}
\hline & $\begin{array}{c}\text { Glare vs. cortical } \\
\text { riders }\end{array}$ & $\begin{array}{c}\text { Glare vs. NS } \\
\text { (Group 1) }\end{array}$ & $\begin{array}{c}\text { Glare vs. PSC alone } \\
\text { (Group 2) }\end{array}$ & $\begin{array}{c}\text { Glare vs. NS + PSC } \\
\text { (Group 3) }\end{array}$ & $\begin{array}{c}\text { Glare vs. presence } \\
\text { of PSC }\end{array}$ \\
\hline Odds ratio & 1.2209 & 0.1926 & 1.3037 & 3.4688 & 5.1923 \\
\hline $\begin{array}{l}\text { Confidence interval } \\
(95 \%)\end{array}$ & $0.342-4.354$ & $0.065-0.570$ & $0.134-5.401$ & $1.282-9.351$ & $1.75-15.39$ \\
\hline
\end{tabular}

NS — nuclear sclerosis; PSC — posterior subcapsular cataract

ues among the three morphological groups pre and post-surgery, with and without the induction of glare with BAT. Similarly, Table 2 shows the mean values of the patients pre and post-surgery categorised with the presence or absence of glare. All values of LogMAR or CS in different situations of induc- tion with BAT not only were statistically significant but were also clinically significant. Figure 1 shows the mean improvement in the LogMAR and CS following surgery as compared to the pre-operative values, with and without induction with low and high glare respectively. Table 3 shows the Odd's 
ratio of glare to the presence of the morphological characteristics of the cataract to assess the risk of having glare as a symptom associated with the presence of it. The presence of either cortical riders or PSC is shown to have the associated risk of glare with the presence of PSC alone, showing a 5 fold risk association.

\section{DISCUSSION}

Discomforting or the disabling glare in the visual scene results in sub-optimal visual performance. Disability glare due to light scatter or discomforting glare resulting in an instinctive desire to look away from the light source, both of which can be distracting and blinding in extreme situations. Light scattering is a normal consequence of the aging process, which leads to a patient having a decreased retinal contrast and glare disability [12-15]. Presence of cataractous changes in the lens, increases the intraocular light scatter and thereby reduces retinal image contrast and degradation of visual quality [15-17]. There is no defined cut-off of BCVA to define cataract, although symptomatic patients can complain of glare even without any drop in the measured vision [15]. Patients with significant cataractous change often deal with glare on a daily basis which can be unpleasant depending on the visual needs and demands of the individual.

Cataracts of all types theoretically can drop VA and CS in situations that induce glare [19-23]. The difference between the mean LogMAR vision and CS-induced with a high glare in our study population, showed a statistically significant difference between the pre and post-operative values irrespective of the sub-groups and the morphological types (Tab. 1, Fig. 1). However, this difference was not significant between the pre and post-operative values on induction with low glare. Though glare disability could act as an adjunct tool to VA measurement to advice on cataract surgery, the visual need of the varies with individuals $[20,23]$. The tropical sunny climate of South India and with most patients in our study from an agricultural background is likely the reason for nearly $70 \%$ of our study patients complaining of glare as a symptom. In real-life situations, working in fields under a sunny climate of a tropical region or being on a sunny beach can be considered equivalent to high glare induction $[16,17]$. Though CS and LogMAR vision assessment with and without glare induction provide useful information on the visual disability in day-today activities, neither is quantified in different types of morphological cataracts to advise patients on the requirement of surgery.

All morphological forms of cataract are reported to cause glare disability to varied extents. From clinical experience, one would anticipate patients with PSC to have the maximum effect on the vision when induced with glare $[12,21,22]$. This is evident in our study as well where the glare induced VA and CS in Group 2 and 3 had the highest drop. However, when the patients with glare were compared with the ones who did not complain of glare, the VA and CS showed a statistically significant difference in the measure values (Tab. 2). This difference was greater when induced with high glare and was statistically and clinically more significant. Moreover, the recovery of the VA and CS following surgery in simulated testing (induced glare) conditions, are indirect measures of the glare disability in day today activities. Studies have reported a significant drop of CS in patients even with the presence of milder forms of PSC $[19,21,22]$ again a consistent finding as seen in our study with Group 2 (PSC alone). Brightness acuity tester in conjunction with CS has been reported to be more sensitive than VA alone especially with VA $\geq 20 / 80[8,18,21]$. The odds of having glare as a symptom in our study was the highest in patients with PSC, and is again the highest in our study, as seen to be three to five times in these patients (Tab. 3). The strong influence of the PSC to the visual symptoms resulting in decreased VA and impairment of CS can be attributed to the proximity of the location of PSC to the nodal point.

In real-life situations, one would expect a combination of NS with PSC to affect the CS more than either of the morphology alone. In our study population, the LogMAR vision seems most affected in group 3, whereas it is less affected with a similar pattern in the other two morphological groups (Fig. 1). Similarly, CS is affected most in Group 2 (presence of PSC only) and group 3 (PSC in association with NS), as compared by NS alone (Group 1) (Fig. 1). Majority of patients (47 patients, 60.3\%) in our study had a combination of NS with PSC, which is a true representation of the distribution of patients seeking surgery in routine practice [22, 24, 25]. When induced with high glare, Group 1 had a drop in the LogMAR (0.16) and CS (0.50), Group 2 with LogMAR (0.14) and CS (0.62) and Group 3 had a drop in LogMAR (0.20) and CS (0.54) respectively (Tab. 1). With each letter valued to be 0.02 units in LogMAR assessment, an average drop of about 
9 letters $(\mathrm{p}<0.05)$ is evident in our study population (Tab. 1). This is equivalent to a 2 lines drop in LogMAR VA assessment, which is clinically significant in any testing conditions. Similarly, an average of 0.54 drop in the CS, translates to around $3.6(\mathrm{p}<0.05)$ step drop with the Pelli-Robson chart in our study population. This deterioration on induced glare testing is clinically significant and could be extremely bothersome to the patients in the day-today activities. Though the change in the values in the three groups are linear with the induction of high glare, the visual degradation of LogMAR VA and the CS are not similar and may not be to the same extent. In a clinical setup and in the evaluation of the patients towards cataract surgeries, both glare induced VA and CS have its advantages to quantify the change and one cannot be ignored over the information obtained from the other.

Symptomatic patients with a significant drop in the CS but not with LogMAR are the group of patients seem to present late in the course of the disease. With slow progress in cataractous changes, the individual may fail to notice the change in the quality of the image. This probably is because such patients are getting neuro-acclimatised over time and the sensory image may be regarded as "acceptably clear" due to gradual habituation and tolerance of the individual. The glare induced VA and CS drop, simulate the real-life scenarios of patients with symptomatic cataracts, and would better correlate to the symptoms to advise patients with visual disability. The patients with reasonably good pre-operative VA and have opted for surgery had the greatest drop in their CS ascertains the fact stronger. Since our sample only included patients who presented for surgery, it may be interpreted vice versa. This retrospectively suggests that the additional contribution of cataract to the glare and why the patients are symptomatic despite a good measured VA.

To quantify the quality of vision by a single parameter is often difficult and this statistically significant effect of cataract in the vision parameters supports the clinical relevance of measuring the same with glare induction $[15,17,21]$. It would be prudent to test glare induced VA and CS degradation along with the routine vision assessment, which will help us to understand the symptomatology better in patients presenting with symptoms of cataract. Testing VA and CS with BAT in patients who request surgery at good levels of vision can give us a better insight into why these patients want surgery and to understand the visual change characteristics. A drop in vision on induced glare testing among such patients can then justify advising surgery. However, it is not true otherwise, to use BAT testing to justify cataract surgery in patients who have do not have symptoms. VA and CS degradation with glare induction will act as more sensitive methods of testing visual function than the routine measurements of the high contrast based VA measurements alone. Done routinely, glare testing will predict real-life visual disability better in patients who have cataracts with symptoms.

Limitation of our study includes evaluating with our working conditions, which were possibly different the other studies (as all the studies have not reported the ambient intensity), which could have altered the absolute value of BAT. Our study included only patients admitted for cataract surgeries and hence extrapolation of these observations to a general population should be done with caution as this may not represent the true distribution of an epidemiological cataract population.

\section{CONCLUSIONS}

Cataracts affect vision and contrast to a greater extent in conditions of high glare and bright lighting. The presence of PSC either alone or in combination with NS has a significant effect on the glare induced CS as well as the VA of an individual. Performing a glare induced VA and CS testing in patients presenting with cataracts for advice, are sensitive ancillary measurements that will simulate real-life situations and will provide a comprehensive assessment of vision disability affecting the daily routine.

\section{Conflict of interests}

The authors have not conflicts of interests to disclose.

\section{REFERENCES}

1. Frisén L, Frisén M. How good is normal visual acuity?. A study of letter acuity thresholds as a function of age. Albrecht Von Graefes Arch Klin Exp Ophthalmol. 1981; 215(3): 149-157, doi: 10.1007/BF00413146, indexed in Pubmed: 6908464.

2. Bailey IL, Jackson AJ. Changes in the clinical measurement of visual acuity. J Phys: Conference Series. 2016; 772: 012046, doi: 10.1088/1742-6596/772/1/012046.

3. Colenbrander A. The Historical Evolution of Visual Acuity Measurement. Vis Impair Res. 2009; 10(2-3): 57-66, doi: 10.1080/13882350802632401.

4. Brown B, Yap MK. Differences in visual acuity between the eyes: determination of normal limits in a clinical population. Ophthalmic Physiol 0pt. 1995; 15(3): 163-169, doi: 10.1046/j.14751313.1995.9590568m.x, indexed in Pubmed: 7659416.

5. Pointer JS. Evaluating the visual experience: visual acuity and the visual analogue scale. Ophthalmic Physiol 0pt. 2003; 23(6): 547-552, doi: 10.1046/j.1475-1313.2003.00152.x, indexed in Pubmed: 14622359. 
6. Cvintal V, Delvadia R, Sun Y, et al. Contrast Sensitivity in Patients with Cataract: Comparing Pelli-Robson with SPARCS Testing Methods. Invest Ophthalmol Vis Sci. 2014; 55: 758.

7. Abrahamsson M, Sjöstrand J. Impairment of contrast sensitivity function (CSF) as a measure of disability glare. Invest Ophthalmol Vis Sci. 1986; 27(7): 1131-1136, indexed in Pubmed: 3721791.

8. Bal T, Coeckelbergh T, Van Looveren J, et al. Influence of cataract morphology on straylight and contrast sensitivity and its relevance to fitness to drive. Ophthalmologica. 2011; 225(2): 105-111, doi: 10.1159/000317076, indexed in Pubmed: 20881445.

9. Elliott DB, Bullimore MA. Assessing the reliability, discriminative ability, and validity of disability glare tests. Invest Ophthalmol Vis Sci. 1993; 34(1): 108-119, indexed in Pubmed: 8425818.

10. Stifter E, Sacu $S$, Thaler A, et al. Contrast acuity in cataracts of different morphology and association to self-reported visual function. Invest Ophthalmol Vis Sci. 2006; 47(12): 5412-5422, doi: 10.1167/ iovs.05-1564, indexed in Pubmed: 17122131.

11. Williamson TH, Strong NP, Sparrow J, et al. Contrast sensitivity and glare in cataract using the Pelli-Robson chart. $\mathrm{Br} \mathrm{J}$ Ophthalmol. 1992; 76(12): 719-722, doi: 10.1136/bjo.76.12.719, indexed in Pubmed: 1486072.

12. Shandiz JH, Derakhshan A, Daneshyar A, et al. Effect of cataract type and severity on visual acuity and contrast sensitivity. J Ophthalmic Vis Res. 2011; 6(1): 26-31, indexed in Pubmed: 22454703.

13. Elliott $D B$, Hurst MA. Simple clinical techniques to evaluate visual function in patients with early cataract. Optom Vis Sci. 1990; 67(11): 822-825, doi: 10.1097/00006324-199011000-00006, indexed in Pubmed: 2250890.

14. Adamsons IA, Vitale S, Stark WJ, et al. The association of postoperative subjective visual function with acuity, glare, and contrast sensitivity in patients with early cataract. Arch Ophthalmol. 1996; 114(5): 529-536, doi: 10.1001/archopht.1996.01100130521004, indexed in Pubmed: 8619761.

15. Aslam TM, Haider D, Murray IJ. Principles of disability glare measurement: an ophthalmological perspective. Acta Ophthalmol Scand. 2007; 85(4): 354-360, doi: 10.1111/j.1600-0420.2006.00860.x, indexed in Pubmed: 17313443.
16. Bailey IL, Bullimore MA. A new test for the evaluation of disability glare. Optom Vis Sci. 1991; 68(12): 911-917, doi: 10.1097/00006324199112000-00001, indexed in Pubmed: 1787947.

17. Prager TC, Urso RG, Holladay JT, et al. Brightness acuity test and outdoor visual acuity in cataract patients. J Cataract Refract Surg. 1987; 13(1): 67-69, doi: 10.1016/s0886-3350(87)80016-0, indexed in Pubmed: 3559957.

18. Wood JM, Carberry TP. Bilateral cataract surgery and driving performance. Br J Ophthalmol. 2006; 90(10): 1277-1280, doi: 10.1136/ bjo.2006.096057, indexed in Pubmed: 16825273.

19. Elliott DB, Gilchrist J, Whitaker D. Contrast sensitivity and glare sensitivity changes with three types of cataract morphology: are these techniques necessary in a clinical evaluation of cataract? Ophthalmic Physiol Opt. 1989; 9(1): 25-30, doi: 10.1111/j.1475-1313.1989. tb00800.x, indexed in Pubmed: 2594373.

20. Jaffe NS. Glare and contrast: indications for cataract surgery. J Cataract Refract Surg. 1986; 12(4): 372-375, doi: 10.1016/s08863350(86)80098-0, indexed in Pubmed: 3735114.

21. Stifter E, Sacu S, Weghaupt H. Functional vision with cataracts of different morphologies: comparative study. J Cataract Refract Surg. 2004; 30(9): 1883-1891, doi: 10.1016/j.jcrs.2004.01.038, indexed in Pubmed: 15342050.

22. Chua BE, Mitchell P, Cumming RG. Effects of cataract type and location on visual function: the Blue Mountains Eye Study. Eye (Lond). 2004; 18(8): 765-772, doi: 10.1038/sj.eye.6701366, indexed in Pubmed: 15044934.

23. Fujikado T, Kuroda T, Maeda N, et al. Light scattering and optical aberrations as objective parameters to predict visual deterioration in eyes with cataracts. J Cataract Refract Surg. 2004; 30(6): 1198-1208, doi: 10.1016/j.jcrs.2003.12.023, indexed in Pubmed: 15177593.

24. Rubin GS, Adamsons IA, Stark WJ. Comparison of acuity, contrast sensitivity, and disability glare before and after cataract surgery. Arch Ophthalmol. 1993; 111(1): 56-61, doi: 10.1001/ archopht.1993.01090010060027, indexed in Pubmed: 8424725.

25. Fu J, Wang J, Wang NI, et al. [Early clinical evaluation of visual function in patients with age-related cataract]. Zhonghua Yan Ke Za Zhi. 2006; 42(3): 236-240, indexed in Pubmed: 16643756. 